\title{
An Updated Review: Androgens and Cognitive Impairment in Older Men
}

\author{
Zhonglin Cai and Hongjun $\mathrm{Li}^{*}$ \\ Department of Urology, Peking Union Medical College Hospital, Peking Union Medical College, Chinese Academy of Medical \\ Sciences, Beijing, China
}

Androgens are some of the most important sex hormones in men, and they maintain important physiological activities in the human body. Cognitive impairment is one of the most common manifestations of aging in the elderly population and an important factor affecting the quality of life of elderly individuals. The levels of sex hormones in elderly people decrease with age, and low levels of androgens in older male individuals have been closely linked to the development of cognitive impairment. Basic studies have shown that androgens have neuroprotective effects and that androgen deficiency impairs cognitive function by increasing oxidative stress and decreasing synaptic plasticity, among other effects. Additionally, clinical studies have also shown that androgen deficiency is closely related to cognitive impairment. This article reviews the relationship between low

OPEN ACCESS

Edited by:

Fabio Monzani,

University of Pisa, Italy

Reviewed by:

Rong Yuan,

Southern Illinois University

Carbondale, United States

Vincenzo Triggiani,

University of Bari Aldo Moro, Italy

*Correspondence:

Hongjun Li

lihongjun@pumch.cn

Specialty section:

This article was submitted to

Endocrinology of Aging,

a section of the journal

Frontiers in Endocrinology

Received: 27 July 2020

Accepted: 12 October 2020

Published: 13 November 2020

Citation:

Cai Z and Li H (2020) An Updated

Review: Androgens and Cognitive

Impairment in Older Men.

Front. Endocrinol. 11:586909.

doi: 10.3389/fendo.2020.586909 androgen levels and cognitive impairment, their potential mechanisms, and the effects of testosterone supplementation in improving cognition.

Keywords: androgen, cognitive impairment, aging, older men, molecular mechanism

\section{INTRODUCTION}

Human aging is an inevitable process (1). As aging occurs, the gonads decrease in function, and there is a decrease in the levels of sex hormones (2). The most important sex hormones in men are androgens, which are involved in maintaining the normal functions of multiple tissues and organs in human physiology (3). In older men, in addition to their effects on the reproductive system, low levels of androgens have been reported to increase the risk for many aging-related diseases in other systems, such as tumors, diabetes mellitus and cardiovascular diseases $(4,5)$. Therefore, androgens are vital to older men.

Androgens mainly include testosterone produced by Leydig cells, the testosterone metabolite dihydrotestosterone (DHT), adrenal-derived dehydroepiandrosterone (DHEA), androstenedione, androstenediol, and androstenone. The brain can synthesize neurosteroids using peripheral sex hormones, which can also be synthesized de novo by using cholesterol in the brain $(6,7)$. Neurosteroids synthesized in the brain include androgens such as testosterone, $3 \alpha$-androstanediol, DHEA, and allopregnanolone, which play an important role in the maintenance of brain function (8). Androgens can improve the biological activity of cells by increasing the production of ATP in the mitochondria and can also increase antioxidant activity to regulate redox homeostasis, thereby exerting a neuroprotective effect $(9,10)$. The cerebral vasculature is also the target of androgens, which increase vascular tone, enhance angiogenesis and cerebral vascular remodeling, reduce vascular damage by attenuating oxidative stress, and maintain the integrity of the blood-brain barrier, thereby exerting additional neuroprotective effects (11). In the hippocampus of the brain, testosterone can improve 
synaptic plasticity and prevent neuronal cell death. DHT induces circuit modifications by changing the number of excitatory spine synapses in a paracrine manner, which in turn affects the cognitive function of the brain (12).

Cognitive function is the result of high-level neural activity in the human brain. It mainly involves verbal, spatial and memory ability (13). Therefore, the manifestations of cognitive impairment are diverse and often appear in multiple forms. Among women, although androgen is not main sex hormone, it has been demonstrated that androgen deficiency is closely related to cognitive impairment (14). For elderly men, in addition to brain aging causing cognitive dysfunction (15), low androgen levels caused by aging can further aggravate cognitive decline in the brain (16). Therefore, in older men, low levels of androgens and cognitive impairment also have a close relationship. This article will objectively discuss the relationship between androgens and cognitive function in older men, potential mechanisms, and the roles of testosterone supplementation in improving cognition.

\section{METHODS}

The narrative review was conducted on extracted and summarized findings from relevant literature by an electronic search of the PubMed databases. The electronic search was performed according to the following keywords: (androgen OR testosterone OR hypogonadism) AND (cognition OR dementia OR Alzheimer's disease). Based on the aim of this narrative review, the findings published after 2000 were recurrently reviewed by considering title and abstract and evaluating full texts, and relevant studies were selected. Additional studies were also selected from the reference lists in selected studies.

\section{Relationship Between Decreased Androgens and Impaired Cognition in the Normal Aging Process}

Sex hormones are regulated and produced by the gonads through the gonadal (hypothalamus-pituitary-testis) axis in males. Any factors that affect the gonadal axis, including aging and gonadalrelated diseases, can cause an imbalance in the levels of sex hormones, such as testosterone, DHEA, luteinizing hormone (LH) and follicle-stimulating hormone (FSH). Hypogonadism is a clinical syndrome due to androgen deficiency caused by failure of testicular function, and its incidence was $38.7 \%$ in males aged $>45$ years (total testosterone level $<300 \mathrm{ng} / \mathrm{ml}$ ) (17). Clinically, hypogonadism due to aging is called late onset hypogonadism. It has been reported that the incidence of testosterone deficiency is approximately $20 \%$ in men aged 60 years and increases to $50 \%$ in 80 -year-old men (18). Therefore, androgen deficiency caused by aging cannot be ignored due to the high incidence in older men. Although aging can directly lead to cognitive decline, androgen deficiency is considered to be another important cause of cognitive decline in older men (19). In studies of cognitive function evaluated by the MMSE and sex hormone levels in older men, the levels of sex hormones, including testosterone, DHT, estradiol (E2), estrone (E1), LH, and FSH, change over time (20). These changes have been related to declines in cognitive ability (20). However, interestingly, only serum testosterone, DHT and calculated FT are associated with decreased cognitive function after correcting for confounding factors (20). This finding demonstrated that androgen levels are closely related to cognitive impairment in elderly men.

Various types of androgen have been found to be associated with cognition function. A meta-analysis of seven prospective cohort studies has shown that low levels of plasma testosterone are significantly associated with an increased risk of $\mathrm{AD}$ in older men $(\mathrm{RR}=1.48,95 \% \mathrm{CI} 1.12-1.96, \mathrm{P}=0.006)(21)$. In addition to total testosterone (TT), plasma DHT, and FT in elderly men are also significantly correlated with cognitive decline according to the MMSE score (20). It has been shown that the decrease in TT and FT levels in plasma, which is independent of the relevant clinical and biochemical factors, is associated with an increased risk for dementia in older men (22), and the risk ratios of TT and FT for dementia were 1.14 and 1.18, respectively (23). Additionally, despite a lack of research on endogenous DHT, which can be converted from testosterone, and cognitive dysfunction, $5 \alpha$ reductase inhibitor-induced DHT deficiency has been shown to increase the risk of dementia in elderly men (24), suggesting that testosterone deficiency may lead to a lack of DHT, which is closely related to cognitive dysfunction. DHEA and its sulfated form (DHEA-S) are important neurosteroids that regulate brain development and function. A correlation between serum DHEA-S levels and working memory has been found to be strong in males (25). Thus, androgen plays an important role in cognitive function, and low androgen levels are an important cause of cognitive impairment in older men.

SHBG is the main transport for testosterone and regulation of total testosterone bioactivity (26). In older men, with increasing age, the level of SHBG increases. Additionally, compared with healthy aging males, the level of SHBG in elderly AD patients increased significantly (27). However, levels of SHBG have no relationship with cognitive decline in patients with cognitive impairment according to the Alzheimer's Disease Assessment Scale-Cognitive section (28). Interestingly, it has been found that in aging males, decreased bioavailable testosterone (BT), a non-SHBG-bound form of testosterone, is closely correlated with cognitive function according to the Standardized Mini Mental Test for the diagnosis of dementia (26). Low BT was associated with a greater risk for dementia (HR 1.29, 95\% CI 1.03-1.62, P < 0.01), and the above relationship is stronger in men over 80 years of age (29). Therefore, with aging, SHBG levels increase, BT may be a neglected important cause of cognitive impairment in older men.

\section{More Clinical Proof for Androgen Reduction and Cognitive Impairment}

Accumulative studies have found that androgen levels decrease in the context of a variety of diseases and corresponding treatments, including schizophrenia, acquired immune deficiency syndrome, multiple sclerosis, hypogonadism, and acute lymphoblastic leukemia $(23,30-32)$. These clinical studies have also found that these populations with low androgen levels have a higher risk of cognitive impairment, such as spatial memory and attention deficit. As a common disease in elderly patients, type 2 diabetes mellitus has been shown by an increasing number of studies to lead to lower 
testosterone levels in men, increase testosterone resistance, and increase the incidence of Alzheimer's disease (AD), a serious cognitive impairment disease (33).

Prostatic hyperplasia is a common disease in older men and often causes lower urinary tract symptoms (LUTS). $5 \alpha$ reductase inhibitors are commonly used in the treatment of male prostatic hyperplasia. They can reduce the level of DHT. The risk for dementia in patients on $5 \alpha$ reductase inhibitors is 2.18 and 1.52 times that of patients in the first and second years, respectively (24). This suggests that $5 \alpha$ reductase inhibitors may increase the risk of dementia by reducing the level of DHT.

Prostate cancer $(\mathrm{PCa})$ is a common cancer in elderly men. $\mathrm{ADT}$ is an important treatment for inhibiting the growth of $\mathrm{PCa}$ that functions by lowering testosterone levels. Significant neurophysiological and psychological problems occur after ADT (34). Accumulative studies have shown that compared with those of patients without ADT, the cognitive functions, including language ability, short-term memory, prospective memory, mental flexibility, inhibitory control and emotional psychology, of patients with ADT are significantly impaired (34-39). After ADT treatment, cognitive impairment occurs within 6 and 12 months, and the risk for dementia is greatest when ADT exceeds 12 months $(38,39)$. Compared with non-ADT patients, the risk for dementia in patients with ADT increases by 4.4 and $5.8 \%$ within follow-up periods of 5 and 8.3 years, respectively (38-40). Additionally, generally, the higher the dose of ADT is, the higher the risk of dementia (40). AD is a serious type of dementiarelated disease. Multiple studies have also shown that $\mathrm{AD}$ risk in the ADT group is 1.14-1.84 times higher than that in the non-ADT group after adjusting for confounding factors (40-42). Patients over 70 years of age have the greatest risk for AD after ADT compared with patients under 70 years of age (43). However, due to heterogeneity of general characteristics and study methods, some studies have shown that ADT is not associated with dementia or AD (44-48). A recent meta-analysis with high evidence grade confirmed that ADT increased the risk for dementia in PCa patients (49), suggesting that low androgen derived from ADT is an important cause of cognitive dysfunction. Additionally, changes in tissue structure after ADT support cognitive dysfunction. It has been found that ADT treatment can induce a significant reduction in gray matter volume and an increase in white matter lesion load in multiple regions, including the frontopolar cortex, dorsolateral prefrontal cortex, and primary motor cortex $(50,51)$. Thus, cognitive set shifting is impaired, and responses evoked by ventral hippocampus afferents are attenuated, resulting in cognitive dysfunction (52). Therefore, low androgen caused by ADT is closely related to cognitive impairment in male patients.

\section{Mechanism of Low Androgen-Induced Cognitive Impairment}

In the $\mathrm{AD}$ rat model produced by intraventricular injection of streptozotocin, there is severe deterioration in the memory of the rats after testicular castration, and this memory could be significantly restored by supplementation with testosterone (53), suggesting that testosterone can improve cognitive and memory disorders. Androgen plays biological roles in the brain mainly by binding to androgen receptors (ARs), which are widely expressed in multiple brain regions, including the hippocampus and prefrontal cortex (54). Clinical AD samples have shown that $\mathrm{AD}$ patients have multiple single nucleotide polymorphisms in ARs in multiple tissues, including the brain and that the level of AR expression is reduced (30). It has further been suggested that androgen binds to ARs in the brain tissue and thus affects cognitive function.

Androgen is closely related to brain beta amyloid $(\mathrm{A} \beta)$ by the AR signaling pathway (55). Reduced androgen levels induce $\mathrm{A} \beta$ accumulation in brain neurons. $\mathrm{A} \beta$ is an important pathological molecule in the brain tissue of patients with $\mathrm{AD}$ and impairs neurons. Hippocampal neurons and their synaptic plasticity are the basis of spatial memory and cognition. Accumulative $\mathrm{A} \beta$ in hippocampal neurons directly disrupts cognition by complicated pathological mechanisms that induce abnormal synaptic structures, synaptic plasticity reduction, and neuroviability impairment (10, 56). It has been found that in male rats treated with testosterone, the expression of $\mathrm{A} \beta 1-42$ protein was significantly decreased. The mechanisms by which testosterone regulates $\mathrm{A} \beta$ levels in neurons are as follows: 1 . Elevating neprilysin to accelerate $A \beta$ clearance (57); 2. Inhibiting $A \beta$ accumulation by increasing $\operatorname{HSP} 70(56,58)$. In addition to the AR signaling pathway, testosterone can clear $\mathrm{A} \beta$ by the estrogen receptor signaling pathway (59). In summary, based on the above mechanisms, androgen contributes to improving cognitive function by improving $\mathrm{A} \beta$-mediated impairment of hippocampal neurons by reducing $\mathrm{A} \beta$ accumulation (Figure 1A).

It is known that increases in oxidative stress can seriously damage brain function $(60,61)$. The levels of reactive oxygen species (ROS) and the number of apoptotic cells in brain tissue are significantly increased in diet-induced obese rats, while the levels of ROS and the number of apoptotic cells are further increased after orchidectomy (ORX) treatment (60). After ORX treatment, the levels of oxidative stress molecules, such as ROS and malondialdehyde, are significantly increased in the hippocampus, leading to the overactivity of glial cells and apoptosis and then hippocampal dysplasia and cognitive decline (62). In rats with intact gonads, chronic intermittent hypoxia $(\mathrm{CIH})$ induces increased levels of oxidative stress in $\mathrm{AD}$ related brain regions, which leads to memory impairments (63). It has been shown that testosterone scavenges free radicals to enhance synaptic plasticity by the AR signaling pathway in the hippocampus (64). In addition, $\mathrm{A} \beta$ can impair mitochondrial function and induce increased oxidative stress. Testosterone could attenuate mitochondrial dysfunction-induced $\mathrm{A} \beta$ and estrogen, which is converted from testosterone, and could improve mitochondrial dysfunction in hippocampal neurons of $\mathrm{AD}$ animals, which is induced by $\mathrm{A} \beta$ or tau protein (65), another important pathological molecule of $\mathrm{AD}$. Conversely, testosterone supplementation can preserve memory function and prevent $\mathrm{CIH}$-induced oxidative stress changes (63). Testosterone could inactivate Bcl-2-related dead cells (Bad) and inhibit apoptosis of cerebellar granule cells induced by oxidative stress, thus alleviating cognitive impairment (66-68). Thus, testosterone can improve cognitive impairment by reducing mitochondrial damage and oxidative stress in neurons (Figure 1B). 


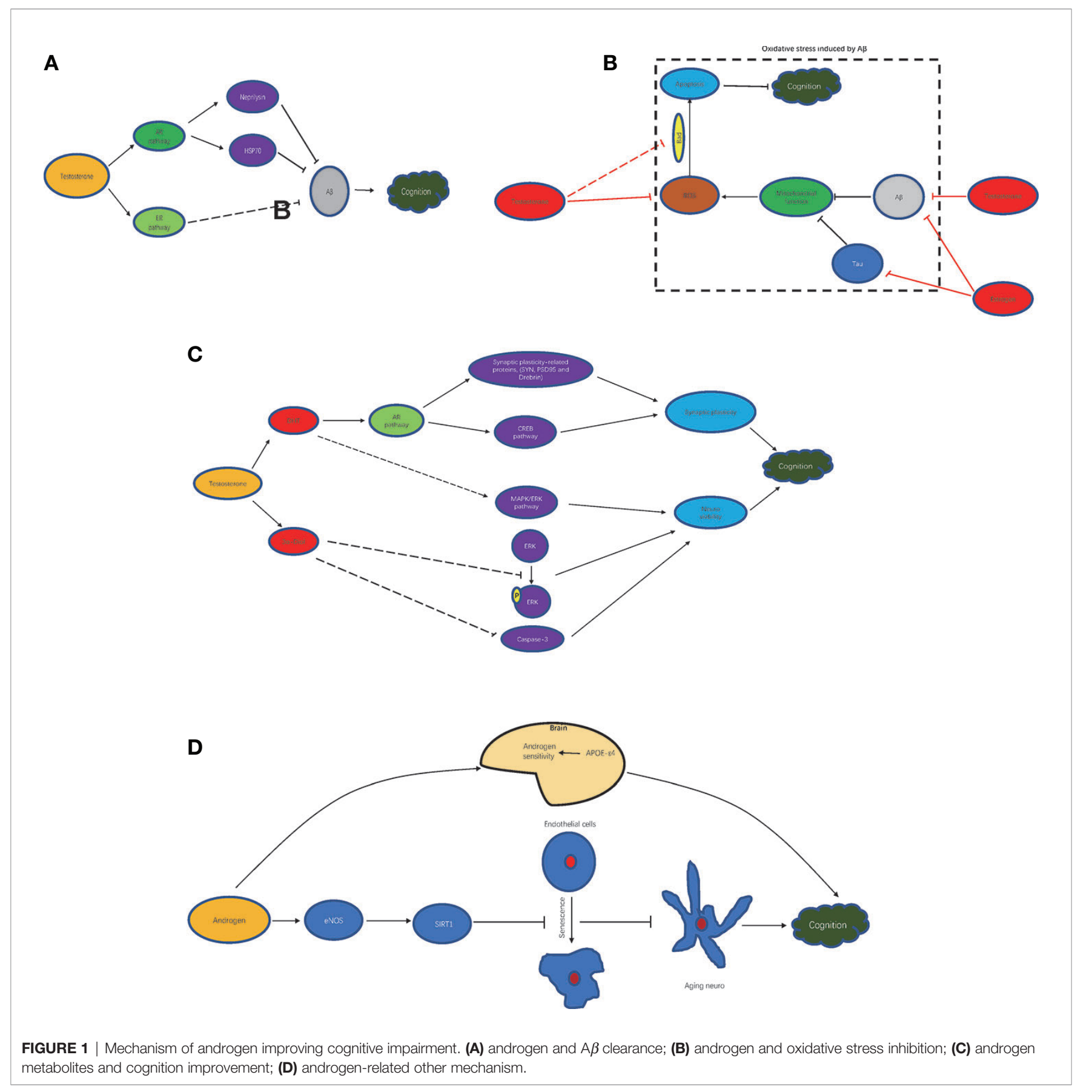

Testosterone metabolites such as DHT, $5 \alpha$-androstane$3 \alpha, 17 \beta$-diol ( $3 \alpha$-diol) also participate in neuroprotection (Figure 1C). DHT enhanced synaptic plasticity-related proteins, such as SYN, PSD95, and Drebrin, and activated the CREB signaling pathway by AR, thereby improving the hippocampal synaptic structure and increasing synaptic plasticity to improve cognitive function (69). Additionally, it also contributed to improving neuroviability by activating the MAPK/ERK signaling pathway. $3 \alpha$-Diol inhibited the delay in ERK phosphorylation and caspase- 3 caused by $\mathrm{A} \beta 42$ and reduced all the cellular activity induced by $\mathrm{A} \beta$ or hydrogen peroxide, thus exerting neuroprotective effects (70).

In addition to the above mechanism, androgen can also improve cognitive function through other molecules and corresponding pathways (Figure 1D). In carriers of APOE- $\epsilon 4$, APOE- $\epsilon 4$ increases the sensitivity of the brain to testosterone, thereby increasing tolerance to the effects of aging produced by lower testosterone levels that lead to cognitive decline (71). In addition, it has shown that aging endothelial cells in the brain can promote the aging of neurons. In aging vascular 
endothelial cells, testosterone induces the expression of SIRT1 by enhancing eNOS activity to inhibit the aging of endothelial cells, thereby inhibiting the aging of neurons and slowing cognitive decline (72).

Thus, basic studies have shown that testosterone, as the main androgen, plays an important neuroprotective role in the brain, especially in the hippocampus. The decrease in androgen levels may be one of the important reasons for cognitive impairment in elderly patients.

\section{Is There a Need for Testosterone Supplementation?}

Basic studies, as reviewed above, have confirmed that testosterone levels are associated with cognitive impairment and that testosterone supplementation has obvious neuroprotective effects. Most clinical studies have also supported the association between low testosterone levels and cognitive impairment. However, clinical studies on testosterone supplementation and improvements in cognitive function in elderly men are inconsistent.

For older men with low testosterone and cognitive impairment, two small-sample studies have shown that testosterone supplementation (50-100 $\mathrm{mg}$ of testosterone daily) results in improvements in global cognition, verbal memory and depressive symptoms $(73,74)$. In another study with 106 elderly patients with testosterone deficiency syndrome, after 8 months of testosterone replacement treatment (injection with $1,000 \mathrm{mg}$ testosterone undecanoate), the total serum testosterone levels significantly increased, depression scores significantly decreased, and cognitive function scores according to the MMSE significantly increased (75). These studies all showed that testosterone supplementation contributes to improving cognitive impairment. However, a largesample prospective study showed that after supplementation with testosterone ( $1 \%$ testosterone gel, $5 \mathrm{~g}$ daily) for 12 months in older men with low testosterone levels and age-related cognitive impairment, there was no significant increase in delayed paragraph recall, visual memory, executive functioning and spatial ability, suggesting that testosterone supplementation was not related to improvements in cognitive functioning (76). The heterogeneity of the above results may be due to different cognitive evaluations, sample sizes, study designs, and methodologies, etc. Meanwhile, a recent meta-analysis of testosterone supplementation in middleaged or aging males with cognitive impairment or dementia also failed to confirm that testosterone supplementation contributes to cognitive improvement (77). Additionally, for older men with low

\section{REFERENCES}

1. Cai Z, Zhang J, Li H. Selenium, aging and aging-related diseases. Aging Clin Exp Res (2019) 31(8):1035-47. doi: 10.1007/s40520-018-1086-7

2. Ishay A, Tzemah S, Nitzan R, Jehassi A, Cohen M. Testosterone Management in Aging Males: Surveying Clinical Practices of Urologists and Endocrinologists in Israel. Sex Med (2019) 7(4):409-17. doi: 10.1016/j.esxm.2019.06.011

3. Boese AC, Kim SC, Yin KJ, Lee JP, Hamblin MH. Sex differences in vascular physiology and pathophysiology: estrogen and androgen signaling in health and disease. Am J Physiol Heart Circ Physiol (2017) 313(3):H524-45. doi: 10.1152/ajpheart.00217.2016 androgen and without cognitive impairment, most studies did not provide supporting evidence that testosterone supplementation can enhance cognition (78-80). Interestingly, a meta-analysis of testosterone supplementation and the prevention of cognitive decline showed significant improvements in overall cognitive composite scores, psychomotor speed and executive function in elderly patients with testosterone supplementation (81). In short, although testosterone deficiency is closely related to cognitive impairment, testosterone supplementation for improving cognitive function in aging males remains further clarified.

\section{CONCLUSIONS}

With aging, declines in cognitive function are one of the important factors affecting the quality of life of elderly individuals. Most clinical studies have confirmed that there is a close relationship between low androgen levels and cognitive impairment in elderly individuals; meanwhile, basic research has shown that testosterone contributes to the maintenance of cognitive function, which is further supported by corresponding mechanistic research. Androgen supplementation seems to be a promising treatment for improving cognitive impairment in older men. However, most of the existing clinical studies about androgen supplementation do not support that androgen supplementation can be helpful for cognitive improvement in older men (69-72). Together, androgen deficiency is an important cause of cognitive impairment in older men and should receive attention. More studies of testosterone supplementation in improving cognition are needed.

\section{AUTHOR CONTRIBUTIONS}

ZC collected all related references and drafted the manuscript. HL was responsible for the conception and design of the work. All authors contributed to the article and approved the submitted version.

\section{FUNDING}

This study was funded by the grant from National Natural Science Foundation of China (Grant No. 81871152).
4. Deng C, Zhang Z, Li H, Bai P, Cao X, Dobs AS. Analysis of cardiovascular risk factors associated with serum testosterone levels according to the US 20112012 National Health and Nutrition Examination Survey. Aging Male (2019) 22(2):121-8. doi: 10.1080/13685538.2018.1479387

5. Zhang J, Yang B, Xiao W, Li X, Li H. Effects of testosterone supplement treatment in hypogonadal adult males with T2DM: a meta-analysis and systematic review. World J Urol (2018) 36(8):1315-26. doi: 10.1007/s00345018-2256-0

6. Hojo Y, Kawato S. Neurosteroids in Adult Hippocampus of Male and Female Rodents: Biosynthesis and Actions of Sex Steroids. Front Endocrinol (Lausanne) (2018) 9:183. doi: 10.3389/fendo.2018.00183 
7. MacKenzie G, Maguire J. Neurosteroids and GABAergic signaling in health and disease. Biomol Concepts (2013) 4(1):29-42. doi: 10.1515/bmc-2012-0033

8. Traish AM, Kang HP, Saad F, Guay AT. Dehydroepiandrosterone (DHEA)-a precursor steroid or an active hormone in human physiology. J Sex Med (2011) 8(11):2960-82. quiz 2983. doi: 10.1111/j.1743-6109.2011.02523.x

9. Grimm A, Schmitt K, Lang UE, Mensah-Nyagan AG, Eckert A. Improvement of neuronal bioenergetics by neurosteroids: implications for age-related neurodegenerative disorders. Biochim Biophys Acta (2014) $1842(12 \mathrm{Pt}$ A):2427-38. doi: 10.1016/j.bbadis.2014.09.013

10. Pintana H, Chattipakorn N, Chattipakorn S. Testosterone deficiency, insulinresistant obesity and cognitive function. Metab Brain Dis (2015) 30(4):853-76. doi: 10.1007/s11011-015-9655-3

11. Robison LS, Gannon OJ, Salinero AE, Zuloaga KL. Contributions of sex to cerebrovascular function and pathology. Brain Res (2019) 1710:43-60. doi: 10.1016/j.brainres.2018.12.030

12. Fester L, Rune GM. Sexual neurosteroids and synaptic plasticity in the hippocampus. Brain Res (2015) 1621:162-9. doi: 10.1016/j.brainres.2014.10.033

13. Glisky EL. Changes in Cognitive Function in Human Aging. In: DR Riddle, editor. Brain Aging: Models, Methods, and Mechanisms. Boca Raton (FL): CRC Press/Taylor \& Francis (2007). doi: 10.1201/9781420005523-1

14. Davis SR, Wahlin-Jacobsen S. Testosterone in women-the clinical significance. Lancet Diabetes Endocrinol (2015) 3(12):980-92. doi: 10.1016/ S2213-8587(15)00284-3

15. Bettio LEB, Rajendran L, Gil-Mohapel J. The effects of aging in the hippocampus and cognitive decline. Neurosci Biobehav Rev (2017) 79:6686. doi: 10.1016/j.neubiorev.2017.04.030

16. Giagulli VA, Guastamacchia E, Licchelli B, Triggiani V. Serum Testosterone and Cognitive Function in Ageing Male: Updating the Evidence. Recent Pat Endocr Metab Immune Drug Discov (2016) 10(1):22-30. doi: 10.2174/ 1872214810999160603213743

17. Mulligan T, Frick MF, Zuraw QC, Stemhagen A, McWhirter C. Prevalence of hypogonadism in males aged at least 45 years: the HIM study. Int J Clin Pract (2006) 60(7):762-9. doi: 10.1111/j.1742-1241.2006.00992.x

18. Harman SM, Metter EJ, Tobin JD, Pearson J, Blackman MR. Baltimore Longitudinal Study of A: Longitudinal effects of aging on serum total and free testosterone levels in healthy men. Baltimore Longitudinal Study of Aging. J Clin Endocrinol Metab (2001) 86(2):724-31. doi: 10.1210/jcem.86.2.7219

19. Greene R. Sex steroids and brain functioning in the aging male. Aging Male (2001) 4(1):39-43. doi: 10.1080/tam.4.1.39.43

20. Hsu B, Cumming RG, Waite LM, Blyth FM, Naganathan V, Le Couteur DG, et al. Longitudinal Relationships between Reproductive Hormones and Cognitive Decline in Older Men: The Concord Health and Ageing in Men Project. J Clin Endocrinol Metab (2015) 100(6):2223-30. doi: 10.1210/jc.2015-1016

21. Lv W, Du N, Liu Y, Fan X, Wang Y, Jia X, et al. Low Testosterone Level and Risk of Alzheimer's Disease in the Elderly Men: a Systematic Review and Meta-Analysis. Mol Neurobiol (2016) 53(4):2679-84. doi: 10.1007/s12035-015-9315-y

22. Ford AH, Yeap BB, Flicker L, Hankey GJ, Chubb SAP, Golledge J, et al. Sex hormones and incident dementia in older men: The health in men study. Psychoneuroendocrinology (2018) 98:139-47. doi: 10.1016/j.psyneuen.2018.08.013

23. Bove R, Musallam A, Healy BC, Raghavan K, Glanz BI, Bakshi R, et al. Low testosterone is associated with disability in men with multiple sclerosis. Mult Scler (2014) 20(12):1584-92. doi: 10.1177/1352458514527864

24. Welk B, McArthur E, Ordon M, Morrow SA, Hayward J, Dixon S. The risk of dementia with the use of 5 alpha reductase inhibitors. J Neurol Sci (2017) 379:109-11. doi: 10.1016/j.jns.2017.05.064

25. Chen CY, Wu CC, Huang YC, Hung CF, Wang LJ. Gender differences in the relationships among neurosteroid serum levels, cognitive function, and quality of life. Neuropsychiatr Dis Treat (2018) 14:2389-99. doi: 10.2147/NDT.S176047

26. Kocoglu H, Alan C, Soydan H, Ates F, Adayener C, Eren AE, et al. Association between the androgen levels and erectile function, cognitive functions and hypogonadism symptoms in aging males. Aging Male (2011) 14(4):207-12. doi: 10.3109/13685538.2011.617798

27. Lin KA, Rundel C, Doraiswamy PM. Alzheimer's Disease Neuroimaging I: Serum SHBG Levels are not Associated with Longitudinal Cognitive Decline in Mild Cognitive Impairment. J Alzheimers Dis (2017) 55(3):1123-30. doi: 10.3233/JAD-160513

28. Xu J, Xia LL, Song N, Chen SD, Wang G. Testosterone, Estradiol, and Sex Hormone-Binding Globulin in Alzheimer's Disease: A Meta-Analysis. Curr
Alzheimer Res (2016) 13(3):215-22. doi: 10.2174/156720501366 6151218145752

29. Carcaillon L, Brailly-Tabard S, Ancelin ML, Tzourio C, Foubert-Samier A, Dartigues JF, et al. Low testosterone and the risk of dementia in elderly men: Impact of age and education. Alzheimers Dement (2014) 10(5 Suppl):S306314. doi: $10.1016 /$ j.jalz.2013.06.006

30. Owens SJ, Murphy CE, Purves-Tyson TD, Weickert TW, Shannon Weickert C. Considering the role of adolescent sex steroids in schizophrenia. J Neuroendocrinol (2018) 30(2). doi: 10.1111/jne.12538

31. Laan ETM, Prins JM, van Lunsen RHW, Nieuwkerk PT, Nievaard-Boon MAF. Testosterone Insufficiency in Human Immunodeficiency Virus-Infected Women: A Cross-Sectional Study. Sex Med (2019) 7(1):72-9. doi: 10.1016/ j.esxm.2018.10.002

32. Cheung YT, Chemaitilly W, Mulrooney DA, Brinkman TM, Liu W, Banerjee P, et al. Association between dehydroepiandrosterone-sulfate and attention in long-term survivors of childhood acute lymphoblastic leukemia treated with only chemotherapy. Psychoneuroendocrinology (2017) 76:114-8. doi: 10.1016/ j.psyneuen.2016.11.014

33. Asih PR, Tegg ML, Sohrabi H, Carruthers M, Gandy SE, Saad F, et al. Multiple Mechanisms Linking Type 2 Diabetes and Alzheimer's Disease: Testosterone as a Modifier. J Alzheimers Dis (2017) 59(2):445-66. doi: 10.3233/JAD-161259

34. Wu LM, Tanenbaum ML, Dijkers MP, Amidi A, Hall SJ, Penedo FJ, et al. Cognitive and neurobehavioral symptoms in patients with non-metastatic prostate cancer treated with androgen deprivation therapy or observation: A mixed methods study. Soc Sci Med (2016) 156:80-9. doi: 10.1016/j.socscimed.2016.03.016

35. Gunlusoy B, Ceylan Y, Koskderelioglu A, Gedizlioglu M, Degirmenci T, Ortan P, et al. Cognitive Effects of Androgen Deprivation Therapy in Men With Advanced Prostate Cancer. Urology (2017) 103:167-72. doi: 10.1016/ j.urology.2016.12.060

36. Jarzemski P, Brzoszczyk B, Popiolek A, Stachowicz-Karpinska A, Golota S, Bielinski $\mathrm{M}$, et al. Cognitive function, depression, and anxiety in patients undergoing radical prostatectomy with and without adjuvant treatment. Neuropsychiatr Dis Treat (2019) 15:819-29. doi: 10.2147/NDT.S200501

37. Tae BS, Jeon BJ, Shin SH, Choi H, Bae JH, Park JY. Correlation of Androgen Deprivation Therapy with Cognitive Dysfunction in Patients with Prostate Cancer: A Nationwide Population-Based Study Using the National Health Insurance Service Database. Cancer Res Treat (2019) 51(2):593-602. doi: 10.4143/crt.2018.119

38. Gonzalez BD, Jim HS, Booth-Jones M, Small BJ, Sutton SK, Lin HY, et al. Course and Predictors of Cognitive Function in Patients With Prostate Cancer Receiving Androgen-Deprivation Therapy: A Controlled Comparison. J Clin Oncol (2015) 33(18):2021-7. doi: 10.1200/JCO.2014.60.1963

39. Nead KT, Gaskin G, Chester C, Swisher-McClure S, Leeper NJ, Shah NH. Association Between Androgen Deprivation Therapy and Risk of Dementia. JAMA Oncol (2017) 3(1):49-55. doi: 10.1001/jamaoncol.2016.3662

40. Jayadevappa R, Chhatre S, Malkowicz SB, Parikh RB, Guzzo T, Wein AJ. Association Between Androgen Deprivation Therapy Use and Diagnosis of Dementia in Men With Prostate Cancer. JAMA Netw Open (2019) 2(7): e196562. doi: 10.1001/jamanetworkopen.2019.6562

41. Jhan JH, Yang YH, Chang YH, Guu SJ, Tsai CC. Hormone therapy for prostate cancer increases the risk of Alzheimer's disease: a nationwide 4-year longitudinal cohort study. Aging Male (2017) 20(1):33-8. doi: 10.1080/13685538.2016.1271782

42. Nead KT, Gaskin G, Chester C, Swisher-McClure S, Dudley JT, Leeper NJ, et al. Androgen Deprivation Therapy and Future Alzheimer's Disease Risk. J Clin Oncol (2016) 34(6):566-71. doi: 10.1200/JCO.2015.63.6266

43. Nead KT, Gaskin G, Chester C, Swisher-McClure S, Dudley JT, Leeper NJ, et al. Influence of age on androgen deprivation therapy-associated Alzheimer's disease. Sci Rep (2016) 6:35695. doi: 10.1038/srep35695

44. Marzouk S, Naglie G, Tomlinson G, Duff Canning S, Breunis H, Timilshina N, et al. Impact of Androgen Deprivation Therapy on Self-Reported Cognitive Function in Men with Prostate Cancer. J Urol (2018) 200(2):327-34. doi: 10.1016/j.juro.2018.02.073

45. Alibhai SM, Timilshina N, Duff-Canning S, Breunis H, Tannock IF, Naglie G, et al. Effects of long-term androgen deprivation therapy on cognitive function over 36 months in men with prostate cancer. Cancer (2017) 123(2):237-44. doi: $10.1002 / \mathrm{cncr} .30320$

46. Kao LT, Lin HC, Chung SD, Huang CY. No increased risk of dementia in patients receiving androgen deprivation therapy for prostate cancer: a 5-year follow-up study. Asian J Androl (2017) 19(4):414-7. doi: 10.4103/1008-682X.179528 
47. Baik SH, Kury FSP, McDonald CJ. Risk of Alzheimer's Disease Among Senior Medicare Beneficiaries Treated With Androgen Deprivation Therapy for Prostate Cancer. J Clin Oncol (2017) 35(30):3401-9. doi: 10.1200/JCO.2017.72.6109

48. Robinson D, Garmo H, Van Hemelrijck M, Damber JE, Bratt O, Holmberg L, et al. Androgen deprivation therapy for prostate cancer and risk of dementia. BJU Int (2019) 124(1):87-92. doi: 10.1111/bju.14666

49. Nead KT, Sinha S, Nguyen PL. Androgen deprivation therapy for prostate cancer and dementia risk: a systematic review and meta-analysis. Prostate Cancer Prostatic Dis (2017) 20(3):259-64. doi: 10.1038/pcan.2017.10

50. Yang J, Zhong F, Qiu J, Cheng H, Wang K. Dissociation of event-based prospective memory and time-based prospective memory in patients with prostate cancer receiving androgen-deprivation therapy: a neuropsychological study. Eur J Cancer Care (Engl) (2015) 24(2):198-204. doi: 10.1111/ecc.12299

51. Chao HH, Hu S, Ide JS, Uchio E, Zhang S, Rose M, et al. Effects of androgen deprivation on cerebral morphometry in prostate cancer patients-an exploratory study. PloS One (2013) 8(8):e72032. doi: 10.1371/journal.pone.0072032

52. Sharp AM, Lertphinyowong S, Yee SS, Paredes D, Gelfond J, Johnson-Pais TL, et al. Vortioxetine reverses medial prefrontal cortex-mediated cognitive deficits in male rats induced by castration as a model of androgen deprivation therapy for prostate cancer. Psychopharmacol (Berl) (2019) 236 (11):3183-95. doi: 10.1007/s00213-019-05274-4

53. Seyedreza P, Alireza MN, Seyedebrahim H. Role of testosterone in memory impairment of Alzheimer disease induced by Streptozotocin in male rats. Daru (2012) 20(1):98. doi: 10.1186/2008-2231-20-98

54. Janowsky JS. Thinking with your gonads: testosterone and cognition. Trends Cognit Sci (2006) 10(2):77-82. doi: 10.1016/j.tics.2005.12.010

55. Yao PL, Zhuo S, Mei H, Chen XF, Li N, Zhu TF, et al. Androgen alleviates neurotoxicity of beta-amyloid peptide (Abeta) by promoting microglial clearance of Abeta and inhibiting microglial inflammatory response to Abeta. CNS Neurosci Ther (2017) 23(11):855-65. doi: 10.1111/cns.12757

56. Lau CF, Ho YS, Hung CH, Wuwongse S, Poon CH, Chiu K, et al. Protective effects of testosterone on presynaptic terminals against oligomeric betaamyloid peptide in primary culture of hippocampal neurons. BioMed Res Int (2014) 2014:103906. doi: 10.1155/2014/103906

57. Pike CJ, Carroll JC, Rosario ER, Barron AM. Protective actions of sex steroid hormones in Alzheimer's disease. Front Neuroendocrinol (2009) 30(2):23958. doi: 10.1016/j.yfrne.2009.04.015

58. Zhang Y, Champagne N, Beitel LK, Goodyer CG, Trifiro M, LeBlanc A. Estrogen and androgen protection of human neurons against intracellular amyloid beta 1-42 toxicity through heat shock protein 70. J Neurosci (2004) 24 (23):5315-21. doi: 10.1523/JNEUROSCI.0913-04.2004

59. McAllister C, Long J, Bowers A, Walker A, Cao P, Honda S, et al. Genetic targeting aromatase in male amyloid precursor protein transgenic mice downregulates beta-secretase (BACE1) and prevents Alzheimer-like pathology and cognitive impairment. J Neurosci (2010) 30(21):7326-34. doi: 10.1523/ JNEUROSCI.1180-10.2010

60. Chunchai T, Apaijai N, Keawtep P, Mantor D, Arinno A, Pratchayasakul W, et al. Testosterone deprivation intensifies cognitive decline in obese male rats via glial hyperactivity, increased oxidative stress, and apoptosis in both hippocampus and cortex. Acta Physiol (Oxf) (2019) 226(1):e13229. doi: 10.1111/apha.13229

61. Kamat PK, Kalani A, Rai S, Swarnkar S, Tota S, Nath C, et al. Mechanism of Oxidative Stress and Synapse Dysfunction in the Pathogenesis of Alzheimer's Disease: Understanding the Therapeutics Strategies. Mol Neurobiol (2016) 53 (1):648-61. doi: 10.1007/s12035-014-9053-6

62. Chunchai T, Keawtep P, Arinno A, Saiyasit N, Prus D, Apaijai N, et al. Nacetyl cysteine, inulin and the two as a combined therapy ameliorate cognitive decline in testosterone-deprived rats. Aging (Albany NY) (2019) 11(11):344562. doi: 10.18632/aging.101989

63. Snyder B, Duong P, Trieu J, Cunningham RL. Androgens modulate chronic intermittent hypoxia effects on brain and behavior. Horm Behav (2018) 106:62-73. doi: 10.1016/j.yhbeh.2018.09.005

64. Yan XS, Yang ZJ, Jia JX, Song W, Fang X, Cai ZP, et al. Protective mechanism of testosterone on cognitive impairment in a rat model of Alzheimer's disease. Neural Regener Res (2019) 14(4):649-57. doi: 10.4103/1673-5374.245477

65. Grimm A, Mensah-Nyagan AG, Eckert A. Alzheimer, mitochondria and gender. Neurosci Biobehav Rev (2016) 67:89-101. doi: 10.1016/j.neubiorev.2016.04.012

66. Hammond J, Le Q, Goodyer C, Gelfand M, Trifiro M, LeBlanc A. Testosterone-mediated neuroprotection through the androgen receptor in human primary neurons. J Neurochem (2001) 77(5):1319-26. doi: 10.1046/ j.1471-4159.2001.00345.x

67. Uttara B, Singh AV, Zamboni P, Mahajan RT. Oxidative stress and neurodegenerative diseases: a review of upstream and downstream antioxidant therapeutic options. Curr Neuropharmacol (2009) 7(1):65-74. doi: $10.2174 / 157015909787602823$

68. Ahlbom E, Prins GS, Ceccatelli S. Testosterone protects cerebellar granule cells from oxidative stress-induced cell death through a receptor mediated mechanism. Brain Res (2001) 892(2):255-62. doi: 10.1016/S0006-8993(00)03155-3

69. Pan W, Han S, Kang L, Li S, Du J, Cui H. Effects of dihydrotestosterone on synaptic plasticity of the hippocampus in mild cognitive impairment male SAMP8 mice. Exp Ther Med (2016) 12(3):1455-63. doi: 10.3892/etm.2016.3470

70. Mendell AL, Creighton CE, Kalisch BE, MacLusky NJ. 5alpha-Androstane3alpha,17beta-Diol Inhibits Neurotoxicity in SH-SY5Y Human Neuroblastoma Cells and Mouse Primary Cortical Neurons. Endocrinology (2016) 157(12):4570-8. doi: 10.1210/en.2016-1508

71. Panizzon MS, Hauger R, Xian H, Vuoksimaa E, Spoon KM, Mendoza SP, et al. Interaction of APOE genotype and testosterone on episodic memory in middle-aged men. Neurobiol Aging (2014) 35(7):1778 e1771-1778. doi: 10.1016/j.neurobiolaging.2013.12.025

72. Ota H, Akishita M, Akiyoshi T, Kahyo T, Setou M, Ogawa S, et al. Testosterone deficiency accelerates neuronal and vascular aging of SAMP8 mice: protective role of eNOS and SIRT1. PloS One (2012) 7(1):e29598. doi: 10.1371/journal.pone.0029598

73. Wahjoepramono EJ, Asih PR, Aniwiyanti V, Taddei K, Dhaliwal SS, Fuller SJ, et al. The Effects of Testosterone Supplementation on Cognitive Functioning in Older Men. CNS Neurol Disord Drug Targets (2016) 15(3):337-43. doi: 10.2174/1871527315666151110125704

74. Cherrier MM, Anderson K, Shofer J, Millard S, Matsumoto AM. Testosterone treatment of men with mild cognitive impairment and low testosterone levels. Am J Alzheimers Dis Other Demen (2015) 30(4):421-30. doi: 10.1177/1533317514556874

75. Jung HJ, Shin HS. Effect of Testosterone Replacement Therapy on Cognitive Performance and Depression in Men with Testosterone Deficiency Syndrome. World J Mens Health (2016) 34(3):194-9. doi: 10.5534/wjmh.2016.34.3.194

76. Resnick SM, Matsumoto AM, Stephens-Shields AJ, Ellenberg SS, Gill TM, Shumaker SA, et al. Testosterone Treatment and Cognitive Function in Older Men With Low Testosterone and Age-Associated Memory Impairment. Jama (2017) 317(7):717-27. doi: 10.1001/jama.2017.5245

77. Zhang Z, Kang D, Li H. Testosterone and Cognitive Impairment or Dementia in Middle-Aged or Aging Males: Causation and Intervention, a Systematic Review and Meta-Analysis. J Geriatr Psychiatry Neurol (2020) 891988720933351. doi: 10.1177/0891988720933351

78. Borst SE, Yarrow JF, Fernandez C, Conover CF, Ye F, Meuleman JR, et al. Cognitive effects of testosterone and finasteride administration in older hypogonadal men. Clin Interv Aging (2014) 9:1327-33. doi: 10.2147/CIA.S61760

79. Vaughan C, Goldstein FC, Tenover JL. Exogenous testosterone alone or with finasteride does not improve measurements of cognition in healthy older men with low serum testosterone. J Androl (2007) 28(6):875-82. doi: 10.2164/ jandrol.107.002931

80. Emmelot-Vonk MH, Verhaar HJ, Nakhai Pour HR, Aleman A, Lock TM, Bosch JL, et al. Effect of testosterone supplementation on functional mobility, cognition, and other parameters in older men: a randomized controlled trial. Jama (2008) 299(1):39-52. doi: 10.1001/jama.2007.51

81. Tan S, Sohrabi HR, Weinborn M, Tegg M, Bucks RS, Taddei K, et al. Effects of Testosterone Supplementation on Separate Cognitive Domains in Cognitively Healthy Older Men: A Meta-analysis of Current Randomized Clinical Trials. AmJ Geriatr Psychiatry (2019) 27(11):1232-46. doi: 10.1016/j.jagp.2019.05.008

Conflict of Interest: The authors declare that the research was conducted in the absence of any commercial or financial relationships that could be construed as a potential conflict of interest.

Copyright (c) 2020 Cai and Li. This is an open-access article distributed under the terms of the Creative Commons Attribution License (CC BY). The use, distribution or reproduction in other forums is permitted, provided the original author(s) and the copyright owner(s) are credited and that the original publication in this journal is cited, in accordance with accepted academic practice. No use, distribution or reproduction is permitted which does not comply with these terms. 